\title{
Pure Talocrural Dislocation without Associated Malleolar Fracture
}

\author{
Souleymane Diao, Amadou Ndiassé Kasse*, Jean Claude Sane, Joseph Davy Diouf, \\ Abdoulaye Keita, Pape Matar Fall, Pape Alkaly Diouf, Ndiaga Dieye, Mouhamadou Habib Sy \\ Hôpital Général Idrissa Pouye, University Cheikh Anta Diop, Dakar, Senegal \\ Email: *amadoukasse@hotmail.com
}

How to cite this paper: Diao, S., Kasse, A.N., Sane, J.C., Diouf, J.D., Keita, A., Fall, P.M., Diouf, P.A., Dieye, N. and Sy, M.H. (2020) Pure Talocrural Dislocation without Associated Malleolar Fracture. Open Journal of Orthopedics, 10, 13-20.

https://doi.org/10.4236/ojo.2020.101003

Received: November 12, 2019

Accepted: January 6, 2020

Published: January 9, 2020

Copyright $\odot 2020$ by author(s) and Scientific Research Publishing Inc. This work is licensed under the Creative Commons Attribution International License (CC BY 4.0).

http://creativecommons.org/licenses/by/4.0/

\begin{abstract}
Pure talocrural dislocation is an uncommon injury of the ankle. Malleolar fracture is usually associated. We report two cases of pure talocrural dislocation, to describe its therapeutic and prognostic clinical aspects through a review of the literature.
\end{abstract}

\section{Keywords}

Talocrural, Pure Dislocation, Closed Reduction

\section{Introduction}

Pure talocrural dislocation is the dislocation of the ankle. The talocalcaneal block is expelled out of the mortise which is intact both with regard to malleoli and syndesmosis [1].

It is a simple dislocation compared to subtalar dislocation, which is a double dislocation, and enucleation of the talus which is a triple dislocation.

This is a very rare lesion that occurs in a context of violent trauma. Historically, the first case was published in 1912 by Auvray [2]. It is an emergency whose management, apart from complications (cutaneous opening, vascular and nerve lesions), is most often orthopedic: reduction under general anesthesia followed by a restraint by plaster cast.

Pure talocrural dislocation can compromise the functional development of the ankle due to late complications such as stiffness of the ankle, osteoarthritis or necrosis of the talus.

The goal of this work was to report two cases of pure talocrural dislocation, to describe its therapeutic and prognostic clinical aspects through a review of the literature. 


\section{Our Observations}

\section{Observation 1:}

Mr. H. S. D. 32 years old, with no significant pathological history, has been received at $\mathrm{H} 1$ from a sports-related life-style accident (football). He would have done a faux pas with the foot in inversion. Physical examination at admission noted deformity and swelling of the left ankle without cutaneous opening or vasculoneural involvement.

The palpation and the mobilization of the ankle caused a sharp pain. The $\mathrm{X}$-ray of the ankle showed pure posterior talocrural dislocation without associated bone lesion (Figure 1).

The reduction was carried out in an emergency by maneuvering a boot jack. The control X-ray confirmed the reduction of dislocation (Figure 2).

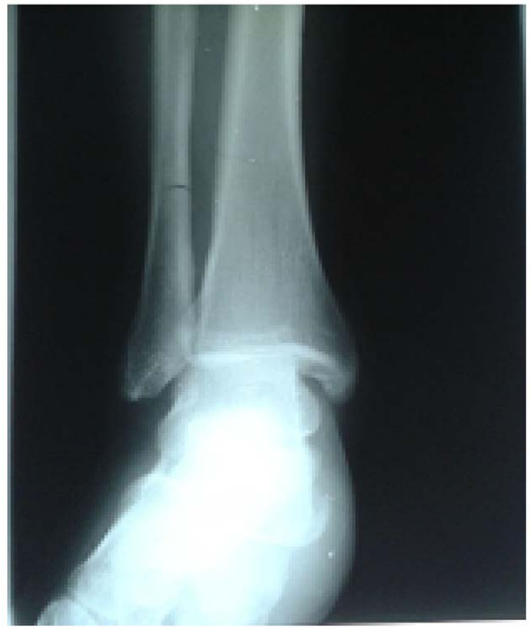

(a)

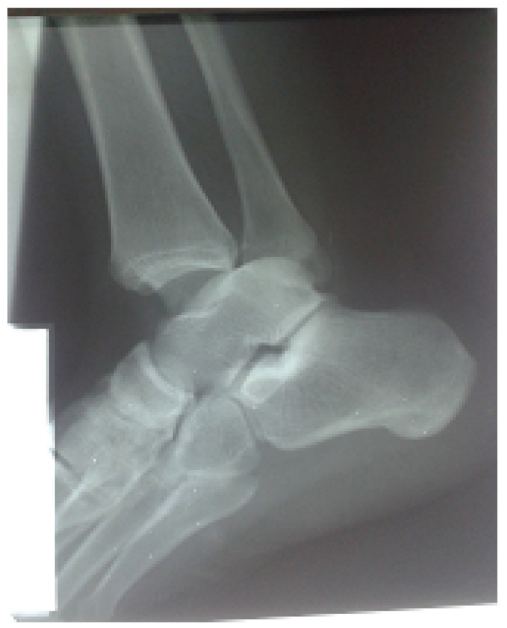

(b)

Figure 1. X-rays of the ankle showing pure posterior Talocrural dislocation ((a) face; (b) profile).

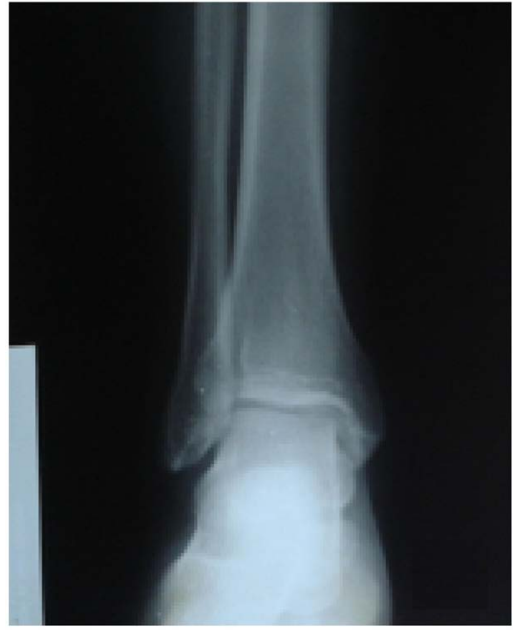

(a)

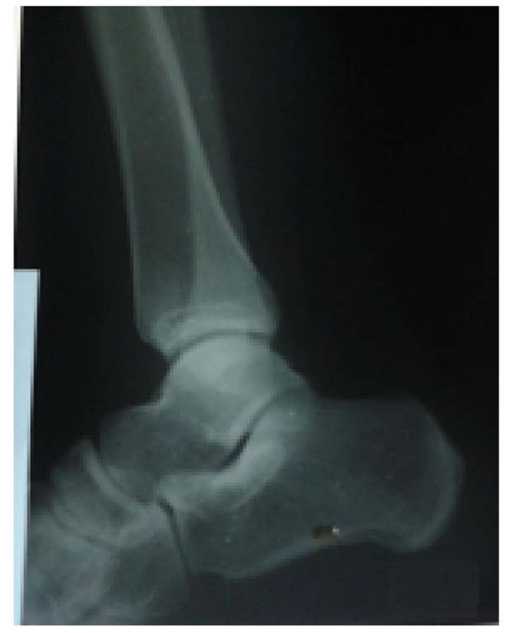

(b)

Figure 2. Post reduction control X-ray ((a) face; (b) profile). 
The arterial duplex scan of the limb was normal. The restraint has been ensured by a plastered boot for 6 weeks. Rehabilitation of the ankle has been started as soon as the cast was removed.

After 2 years of hindsight, the patient had no pain, and he had resumed his sporting and professional activities. The functional results (Figure 3), judged on the Gay and Evrard score (Table 1), were excellent with a score of 15 points. The $\mathrm{X}$-rays of the ankle were normal.
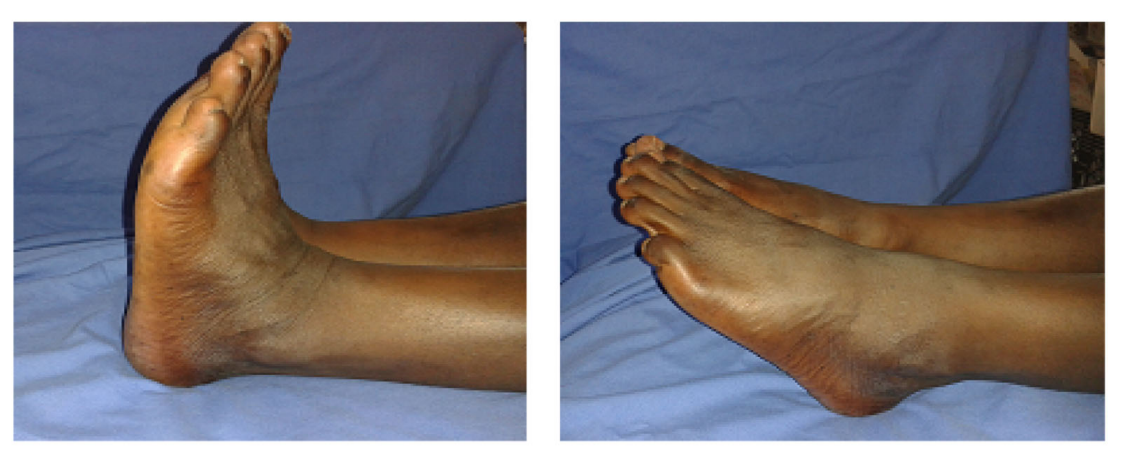

Figure 3. Pictures showing normal mobility of the ankle in hindsight of 2 years.

Table 1. Score of gay and Evrard.

\begin{tabular}{|c|c|c|}
\hline \multicolumn{3}{|c|}{ Criteria of Gay and Evrard } \\
\hline & Subjective Criteria & Points \\
\hline \multirow{3}{*}{ Pain } & Absence of pain & 3 \\
\hline & Pain on uneven ground & 2 \\
\hline & Function pain limiting activity & 1 \\
\hline \multirow{5}{*}{ Instability } & Pain preventing any activity & 0 \\
\hline & Absence of instability & 3 \\
\hline & Instability on rough ground & 2 \\
\hline & Awkward and insecurity Instability & 1 \\
\hline & Instability requiring a stick & 0 \\
\hline \multirow{5}{*}{ Mobility } & Objective Criteria & \\
\hline & Normal mobility & 3 \\
\hline & Mobility equal to or greater than $50 \%$ of normal & 2 \\
\hline & Mobility less than $50 \%$ of normal & 1 \\
\hline & Ankylosis or foot deflection & 0 \\
\hline \multirow{4}{*}{$\begin{array}{c}\text { Edema and } \\
\text { trophic disorders }\end{array}$} & Absence of edema & 3 \\
\hline & Mild or intermittent edema & 2 \\
\hline & Important edema to fatigue & 1 \\
\hline & Important and permanent edema & 0 \\
\hline \multirow{4}{*}{ Professional activity } & Identical activity or profession & 3 \\
\hline & Retained profession with adjustment of the position & 2 \\
\hline & Change of profession or activity & 1 \\
\hline & Impossible professional activity & 0 \\
\hline
\end{tabular}


- Disappearance of tibiotalar spacing and decrease in height of external malleolus (a);

- Displacement of the talo-calcaneo-pedal block behind the tibia (b);

- The malleoluses are intact on both pictures.

\section{Observation 2:}

Mr. B. M. S., 29 years old, with no pathological history reported, was received at $\mathrm{H} 1$ from a home-related accident; he would have done a faux pas when coming down the stairs with foot in inversion. Physical examination at admission noted edema and deformity of the left ankle. The palpation of the ankle was painful. There was no cutaneous opening or vasculoneural lesion.

The X-ray of the ankle showed posterior pure tibiotalar dislocation with talonavicular sprain (Figure 4).

The orthopedic reduction was performed as an emergency, confirmed by an ankle control X-ray (Figure 5).

The restraint has been ensured by a plastered boot for 6 weeks followed by reeducation of the ankle. The patient had resumed his activities. He had no pain or limitation of ankle mobility (Figure 6). The functional results were considered very good according to the score of Gay and Evrard modified by Elisé (score $=15)$, in hindsight of 2 years.

The X-rays of the ankle (face and profile) did not show calcification with regard to ligaments or osteoarthritis.

- Disappearance of joint space;

- Displacement of the talo-calcaneo-pedal block behind the tibia;

- Removal of the talonavicular ligament;

- Two malleoli are intact.

The result was as the following:

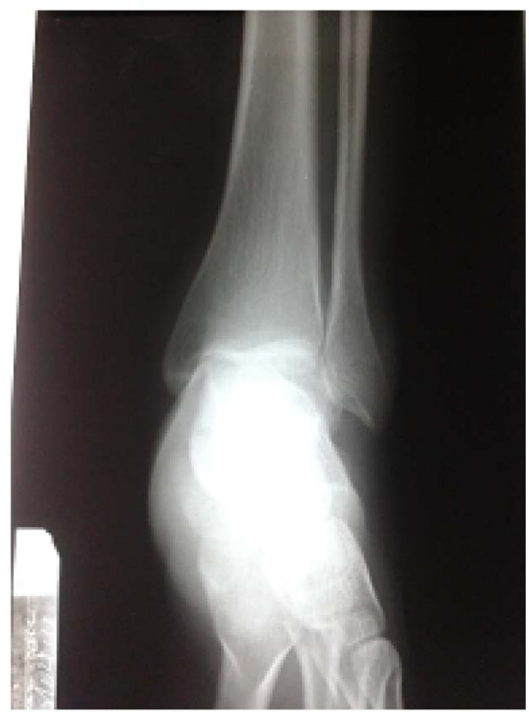

(a)

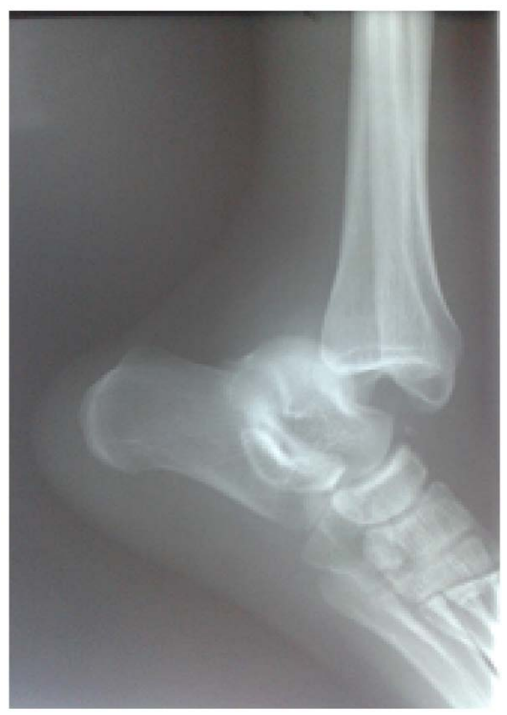

(b)

Figure 4. Ankle X-ray showing posterior pure tibiotalar dislocation with talonavicular sprain ((a) face; (b) profile). 


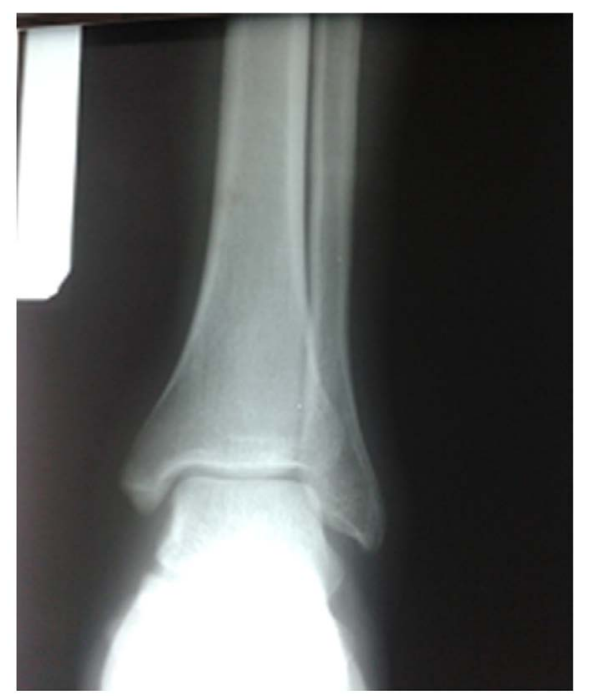

(a)

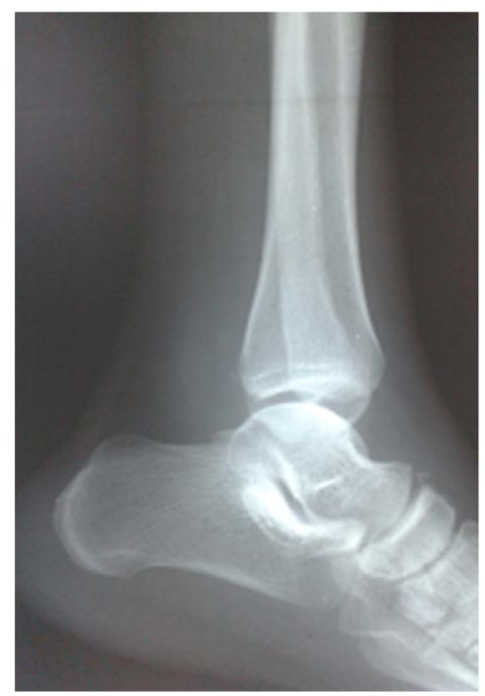

(b)

Figure 5. Post reduction control X-ray ((a) face; (b) profile).
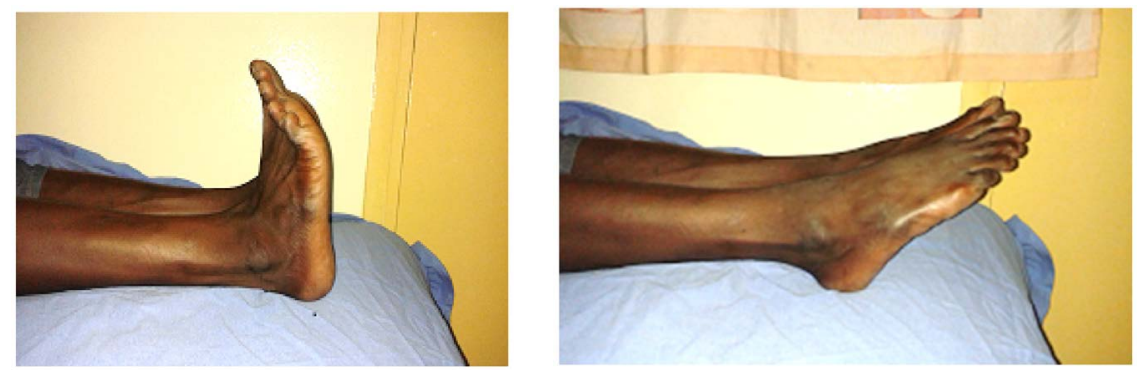

Figure 6. Pictures showing normal mobility of the ankle in hindsight of 2 years.

- $\operatorname{bad}($ score $\leq 4)$;

- passable (score between 5 and 9);

- $\operatorname{good}($ score between 10 and 14);

- and excellent (score $=15)$.

\section{Comments}

- Epidemiology

We have only found two cases over a period of 15 years.

Pure talocrural dislocation is exceptional [3] [4]. The first case documented by X-ray was described in 1913 by Peraire [1]. The work reported in the literature on this lesion is few [5]. Until 1995, only 73 cases were reported [6]. Most studies are based on clinical facts that rarely exceed 2 cases.

Only two series of more than 10 cases [1] [7] have been reported.

The scarcity of this lesion is due to the mechanical stability of the tibiofibular mortise and the resistance of the collateral ligaments, which are as strong as the malleolus, hence the high frequency of the fractures [8].

- Mechanisms and circumstances of occurrence

For the cases of our two patients, these were respectively real-life accidents of 
sports-related and home-related. Talocrural dislocation without associated fracture always occurs in a context of violent trauma [1] [5]. Two-wheeled crashes are the main cause [5] [8] [9] [10], followed by real-life sports-related accidents (football, basketball, volleyball) [4] [10] [11] [12] and falls.

We had two posterior dislocations. In both cases, the mechanism was a misstep associated with inversion of the foot.

According to Fernandes [13], the mechanism of the lesion usually consists of a high energy trauma, which produces sufficient anteroposterior force applied to the foot in maximal plantar flexion resulting in a posterior dislocation of the ankle. The Plantar flexion was considered to be the unstable position of the talocrural joint because the narrow part of the body of the talus lies in the mortise, allowing dislocation.

Fahey and Murphy [5] classified this lesion into five types according to the direction of dislocation: anterior, posterior, medial, lateral and superior. They add the combined forms. The posteromedial variety is the most common [1] [6] [14] [15] [16].

No risk factors were found in any of our patients. Predisposing factors for pure talocrural dislocation are ligament laxity, shortness of the medial malleolus [1] [9] [17] [18], lack of talus cover, history of sprained ankle, and weakness of the peroneal muscles.

- Immediate complications and associated lesions

None early complications have been observed with our patients.

In the literature, cutaneous opening is frequent. It would be of the order of $50 \%$ [1] [2] [6]. The other lesions observed are ligamentous [6] [19], vascular [1] [6] [17] [20] [21] [22], nervous [1] [7] [12] and musculo-tendinous [1] [17] [21] [23] [24].

Lower tibiofibular ligaments are intact in posterior dislocations [18] [20].

- Treatment

The management of pure talocrural dislocation should not be delayed because it is an extreme emergency. Closed dislocations must be treated orthopedically. The reduction is done by maneuvering a boot jack in the posterior varieties, under general anesthesia, knee flexed to release the triceps sural muscle [10] [12]. Most authors recommend emergency reduction followed by plaster cast restraint whether the dislocation is open or closed [7] [25]. Orthopaedic reduction was performed without anaesthesia in both our patients. Indeed our working conditions in our hospitals in sub-Saharan Africa do not often allow us to have a fast general anaesthesia in our patients.

This immobilization must last 6 to 8 weeks [1] [15] [16]. Open dislocations require trimming with drainage, and repair of capsular, neurovascular and musculotendinous lesions. The repair of collateral ligaments is controversial. Finkmeier [26] recommends ligament repair only in case of instability. Other authors advocate their repair in open dislocations [1] [6] [20].

- Prognosis

The functional results were ecxellent for both of our patients in hindsight of 2 
years. Elisé [1] had had satisfactory results (6 very good, 5 good and 1 bad) in 11 cases in hindsight of 11 years. Its complications were stiffness, paresthesia and trophic disorders.

Other late complications are reported in the literature such as ankle osteoarthritis [6], avascular necrosis of the talus [7] and residual ligament laxity [18].

\section{Conclusion}

The talocrural dislocation without malleolar fracture is an exceptional lesion. It occurs in a context of high energy trauma. Its treatment is most often orthopedic with excellent functional results.

\section{Conflicts of Interest}

The authors declare no conflicts of interest regarding the publication of this paper.

\section{References}

[1] Élisé, S., Maynou, C., Mestdagh, H., Forgeois, P. and Labourdette, P. (1998) Les luxations tibio-astragaliennes pures. A propos de 16 observations. Acta Orthopaedica Belgica, 64, 25-34.

[2] Peraire, M. (1913) Luxation tibio-astragalienne avec issue à l'extérieur du péroné non fracturé à travers une boutonnière cutanée. Présentation de malade. Paris Chirurgical, 5, 959.

[3] Lamraski, G. and Clegg, E. (2010) Unusual upward Closed Tibiotalar Dislocation without Fracture: A Case Report. Foot and Ankle Surgery, 16, 44-46.

https://doi.org/10.1016/j.fas.2009.10.012

[4] Wang, Y.T., Wu, X.T. and Chen, H. (2013) Pure Closed Posteromedial Dislocation of the Tibiotalar Joint without Fracture. Orthopaedic Surgery, 5, 214-218.

https://doi.org/10.1111/os.12049

[5] Fahey, J.J. and Murphy, J.L. (1965) Dislocations and Fractures of the Talus. Surgical Clinics of North America, 45, 79-102. https://doi.org/10.1016/S0039-6109(16)37485-0

[6] Garbuio, P., Gérard, F. and Gagneux, E. (1995) Les luxations tibio-tarsiennes pures. À propos de 9 cas. Revue de Chirurgie Orthopédique et Réparatrice de 1 Appareil Moteur, 81, 601-608.

[7] Toohey, J.S. and Worsing Jr., R.A. (1989) A Long-Term Follow-up Study of Tibiotalar Dislocations without Associated Fractures. Clinical Orthopaedics and Related Research, 239, 207-210. https://doi.org/10.1097/00003086-198902000-00023

[8] Wilson, M.J., Michele, A.A. and Jacobson, E.W. (1939) Ankle Dislocations without Fracture. The Journal of Bone and Joint Surgery, 21, 198-204.

[9] Thangarajah, T., Giotakis, N. and Matovu, E. (2008) Bilateral Ankle Dislocation without Malleolar Fracture. The Journal of Foot and Ankle Surgery, 47, 441-446. https://doi.org/10.1053/j.jfas.2008.05.004

[10] Uyar, M., Tan, A., Isler, M. and Cetinus, E. (2004) Closed Posteromedial Dislocation of the Tibiotalar Joint without Fracture. British Journal of Sports Medicine, 38, 342-343. 
[11] Dahmani, O., Ouchrif, Y., Alarab, H., Blanc, S. and Elmrini, A. (2014) Luxation talo-crurale pure chez un footballeur (À propos d'un cas et revue de la littérature). Journal de Traumatologie du Sport, 31, 224-227. https://doi.org/10.1016/j.jts.2014.10.003

[12] Georgilas, I. and Mouzopoulos, G. (2008) Anterior Ankle Dislocation without Associated Fracture. A Case with an 11 Year Follow-up. Acta Orthopaedica Belgica, 74, 266-269.

[13] Fernandes, T.J. (1976) The Mechanism of Talotibial Dislocation without Fracture. The Journal of Bone and Joint Surgery. British Volume, 58,364-365.

[14] Cyteval, C., Blin, D., Sarrrabère, M.P., Larroque, G. and Decoux, E. (2007) Imagerie des traumatismes de la cheville et du pied. Journal de Radiologie, 88, 789-800. https://doi.org/10.1016/S0221-0363(07)91347-5

[15] Lazarettos, I., Brilakis, E. and Efstathopoulos, N. (2013) Open Ankle Dislocation without Associated Malleolar Fracture. The Journal of Foot and Ankle Surgery, 52, 508-512. https://doi.org/10.1053/j.jfas.2013.03.017

[16] Zizah, S., Benabid, M., Mezzani, A., Bennani, A., Lahrach, K., Marzouki, A. and Boutayeb, F. (2012) Un cas rare de luxation tibio-talienne pure. Journal de Traumatologie du Sport, 29, 212-214. https://doi.org/10.1016/j.jts.2012.09.008

[17] Prost à la Denise, J., Tabib, W. and Pauthier, F. (2009) Long-Term Result of a Pure Tibiotalar Dislocation in a Child. Orthopaedics \& Traumatology. Surgery \& Research, 95, 558-562. https://doi.org/10.1016/j.otsr.2009.06.007

[18] Colville, M.R., Colville, J.M. and Manoli, A. (1987) Posteromedial Dislocation of the Ankle without Fracture. The Journal of Bone \& Joint Surgery, 69, 706-710. https://doi.org/10.2106/00004623-198769050-00011

[19] De Mourgues, G., Comtet, J.J. and Leclerc-Chalvet, F. (1969) La luxation tibio-tarsienne pure sans fracture associée. Revue de la littérature à propos d'un cas. Lyon Chirurgical, 65, 661-667.

[20] Mohering, H.D., Tan, R.T., Marder, R.A. and Lian, G. (1994) Ankle Dislocation. Journal of Orthopaedic Trauma, 8, 167-172. https://doi.org/10.1097/00005131-199404000-00015

[21] Tsatedem, F.A., Tsiagadigui, J.G., Ndando, R.P., Arabo, M.S., Bayiha, A. and Kenfack, B. (2012) Décision d'amputation dans la prise en charge initiale d'une luxation ouverte grave de la cheville à propos d'un cas observé à l'Hôpital Laquintinie de Douala suite à un accident par moto-taxi. Pan African Medical Journal, 13, 73.

[22] Tondeur, G., Dufaz, J.P. and Nemry, C.H. (1964) Les luxations pures de la cheville. À propos de deux observations. Acta Orthopaedica Belgica, 30, 410-414.

[23] Kelly, P.J. and Peterson, L.F.A. (1962) Compound Dislocation of the Ankle without Fracture. American Journal of Surgery, 103, 170-172.

https://doi.org/10.1016/0002-9610(62)90481-6

[24] Wehner, J. and Lorenz, M. (1990) Lateral Ankle Dislocation without Fracture. Journal of Orthopaedic Trauma, 4, 362-365. https://doi.org/10.1097/00005131-199004030-00022

[25] Wroble, R.R., Nepola, J.V. and Malvitz, T.A. (1988) Ankle Dislocation without Fracture. Foot \& Ankle International, 9, 64-74. https://doi.org/10.1177/107110078800900202

[26] Finkemeier, C., Engebretsen, L. and Gannon, J. (1995) Tibial-Talar Dislocation without Fracture: Treatment Principles and Outcome. Knee Surgery, Sports Traumatology, Arthroscopy, 3, 47-49. https://doi.org/10.1007/BF01553525 